\title{
Marked seasonality and high spatial variability of protist communities in shallow freshwater systems
}

\author{
Marianne Simon, Purificación López-García, Philippe Deschamps, \\ David Moreira, Gwendal Restoux, Paola Bertolino and Ludwig Jardillier \\ Unité d'Ecologie, Systématique et Evolution, CNRS UMR 8079, Université Paris-Sud, Orsay, France
}

\begin{abstract}
Small eukaryotes have key roles in aquatic ecosystems, influencing their local environment, global biogeochemical cycles and climate. Their impact depends on community structure, which varies along time. However, very few studies take into account temporal variation. This is especially true for small, shallow freshwater systems, which remain largely understudied despite their wide variety, global surface and intense microbial activity. We have monthly followed changes in the community structure of small microbial eukaryotes $(0.2-5 \mu \mathrm{m}$ cell diameter) for 2 years in four ponds and one brook located in North-Western France based on massive 18S rDNA amplicon 454 pyrosequencing. We detected a total of $\mathbf{3 7 4 2}$ stringently defined operational taxonomic units (OTUs) encompassing all recognized eukaryotic supergroups and lineages of uncertain affiliation. Although geographically close, protist communities in the five ecosystems were contrasting, with very few shared OTUs, suggesting that environmental selection mainly drives community structure. The temporal dynamics of different high-rank taxa appeared complex and rapid at monthly scales. Despite this, a clear and reproducible seasonality was observed. As expected, low-abundance OTUs dominated the community. Although some of them appeared sporadically or remained at low frequencies during the survey, others occasionally reached relatively high abundances, sometimes recurrently. This shows that at least a fraction of low-abundance eukaryotes constitutes a seed bank. The annual proportion of primary producers, free-living heterotrophs and parasites appeared remarkably constant among the different ecosystems, suggesting underlying trends of ecosystem carrying capacity for these functional groups.
\end{abstract}

The ISME Journal (2015) 9, 1941-1953; doi:10.1038/ISMEJ.2015.6; published online 13 March 2015

\section{Introduction}

Microbial eukaryotes are versatile components of aquatic environments. They cover multiple roles in these ecosystems, from autotrophy (photosynthesizers) to heterotrophy (predators, decomposers, parasites), or mixotrophy (Zubkov and Tarran, 2008). Protists contribute to biogeochemical cycling, having special impact on global silica and carbon cycles ( $\mathrm{Li}$, 1994; Cloern, 1996; Jordan and Chamberlain, 1997; Jardillier et al., 2010), and influence climate regulation (Simó, 2001). Despite the importance of microbial eukaryotes in the trophic web structure, protist community composition was only explored at very low resolution levels for a long time. Although large phytoplankton and zooplankton morphospecies were identified and counted under the microscope, most small, morphologically difficult-to-distinguish protists were consigned to the 'nanoflagellate' black box. This situation radically changed with the advent of molecular methods based on 18S rDNA

Correspondence: P Lopez-Garcia or L Jardillier, Unité d'Ecologie, Systématique et Evolution, CNRS UMR 8079, Université Paris-Sud, Bâtiment 360, Orsay 91405, France.

E-mail: puri.lopez@u-psud.fr (PL-G) or ludwig.jardillier@u-psud.fr (LJ) Received 16 September 2014; revised 2 December 2014; accepted 11 December 2014; published online 13 March 2015 amplicon sequencing, first through cloning and Sanger sequencing (López-García et al., 2001; Moon-van der Staay et al., 2001), and then through direct high-throughput sequencing techniques (Sogin et al., 2006). Such methods have expanded our capacity to describe community structure to an unprecedented resolution level, unveiling how widely diverse protists, specially the smallest ones, are, allowing the discovery of novel lineages (LópezGarcía et al., 2001; Massana et al., 2004; Lara et al., 2010; Kim and Harrison, 2011) and setting the ground to test biogeography hypotheses (Martiny et al., 2006).

Despite the progress achieved by molecular methods, comparative diversity and biogeography studies most often ignore time scales, leading to potentially biased conclusions (Nolte et al., 2010). Yet, that microbial communities change through time has been known ever since Leeuwenhoek observed the succession and abundance shifts of 'animalcules' in a pepper infusion (Dobell, 1932) and phytoplankton blooms were regularly recorded (Giovannoni and Vergin, 2012). Changes in community composition have been observed at all time scales, within days (Bamforth, 1958; Mangot et al., 2012), weeks (Vigil et al., 2009; Nolte et al., 2010) or months, that is, at annual frequency (Bamforth, 1958; Reid et al., 1990; 
Hitchman and Jones, 2000; Lara et al., 2011). Both abiotic (local rainfall, wind and solar irradiation, $\mathrm{pH}$, temperature and nutrients) and biotic (predation, viral lysis, prey availability) parameters are thought to influence protist community dynamics (Kalff and Knoechel, 1978; Carrias et al., 1998; Lepère et al., 2006; Zhao et al., 2011). However, few detailed, molecular surveys spanning long ( $>1$ year) periods exist, and the parameters considered in these studies explain only very partially the community dynamics (Lepère et al., 2006; Kim et al., 2014). Understanding how environmental parameters influence seasonal variability and shape community structures at pluriannual scale is not only important for comprehensive diversity and biogeography studies but also is crucial to predict the evolution of community compositions on the long run, especially under climate-change scenarios.

Although much less studied than lakes (Richards et al., 2005; Lefranc et al., 2005; Zinger et al., 2012), small, shallow, sometimes ephemeral, freshwater ecosystems (for example, ponds, brooks) appear excellent models to undertake this task for a variety of reasons. They are numerous, so that they cover at least the same surface as larger freshwater bodies (Downing et al., 2006; Downing, 2010). They are diverse, largely because of the influence of benthic and littoral zones (Søndergaard et al., 2005). Because of their limited water volume, they have little buffering capacity, being much more responsive to physicochemical changes (for example, meteorological fluctuations in temperature or solar radiation, nutrient, pesticide or fertilizer inputs, sediment resuspension by animals or storms). Ecologically, they seem very active and are thought to have a significant role in $\mathrm{CO}_{2}$ fixation and, being generally less oxygenated, possibly also in $\mathrm{CH}_{4}$ release (Downing, 2010). In addition, classical studies of the fauna, animal zooplankton and phytoplankton indicate that the number of species per surface unit is much higher in small water bodies (Downing, 2010). Indeed, available molecular studies suggest that this kind of systems constitute reservoirs of protist diversity (Šlapeta et al., 2005; Lara et al., 2011; Simon et al., 2014). Finally, like lakes, because of their discreetness, they would behave as islands where allopatric speciation could in principle occur, being also suitable systems to test hypotheses on microbial biogeography.

In a recent study, we described highly diverse but very contrasting communities of small $(<5 \mu \mathrm{m})$ protists in five shallow freshwater systems ( 4 ponds, 1 brook) located in a small geographic area (2-9.5 km distance) at the Natural Regional Park of the Chevreuse Valley, France (Simon et al., 2014). Here, we analyze how protist community structure assessed by 454 pyrosequencing of $18 \mathrm{~S}$ rDNA amplicons varied in these five systems over 2 years of monthly sampling, and apply multivariate statistics to see whether community dynamics correlate with a variety of regional and local environmental parameters measured in parallel. Despite these communities were spatially very different and underwent complex changes, they showed a clear seasonality.

\section{Materials and methods}

\section{Sampling and measurement of physicochemical parameters}

Samples were collected monthly from April 2011 to April 2013 in four geographically close (2-9.5 km) small shallow ponds and one brook, located at the Natural Regional Park of the Chevreuse Valley (South of Paris, France; http://www.parc-naturel-chevreuse. fr). These systems were characterized by different local environmental conditions (Supplementary Table S1; Simon et al., 2014). Surface water was sampled using sterilized plastic carboys and processed immediately back in the laboratory. Samples were prefiltered through 5 - $\mu$ m pore-size Nucleopore membranes (Whatman, Amersham, UK) and small planktonic cells were collected onto $0.2-\mu \mathrm{m}$ pore-size Nucleopore membranes. Membranes were immediately stored frozen at $-20^{\circ} \mathrm{C}$ until DNA extraction. Water temperature, conductivity, $\mathrm{pH}$ and dissolved oxygen concentrations were measured in situ using a multiparameter probe (Multi350i; WTW, Weilheim, Germany). The concentrations of dissolved orthophosphate $\left(\mathrm{PO}_{4}^{3-}\right)$, organic carbon (DOC), nitrate $\left(\mathrm{NO}_{3}^{-}\right)$, nitrite $\left(\mathrm{NO}_{2}^{-}\right)$and ammonia $\left(\mathrm{NH}_{3}\right)$ in $0.2 \mu \mathrm{m}$ filtered water were measured on the same day using colorimetric tests (Hach-Lange, Düsseldorf, Germany). Chlorophyll a concentration was determined by spectrometry after ethanol pigment extraction from plankton biomass harvested on GF/F filters (Whatman), as described in Simon et al. (2014). Rainfall, mean daily radiation, mean air temperature on the week before sampling and mean wind speed measured at $10 \mathrm{~m}$ above ground on the sampling day were obtained from MétéoFrance (https://donneespubli ques.meteofrance.fr/). Rainfallwas obtained by averaging the data recorded at the three closest meteorological stations: Choisel $\left(48^{\circ} 41^{\prime} 00^{\prime \prime} \mathrm{N}-2^{\circ} 00^{\prime} 00 " \mathrm{E}\right)$, le Perray (48 $\left.41^{\prime} 36^{\prime \prime N}-1^{\circ} 52^{\prime} 00^{\prime \prime E}\right)$ and Saint Arnoult (48 $\left.34^{\prime} 18^{\prime \prime} \mathrm{N}-1^{\circ} 55^{\prime} 54^{\prime \prime} \mathrm{E}\right)$, whereas radiation, temperature and wind speed were measured at station Trappes (484ㄴ' $\left.24^{\prime \prime} \mathrm{N}-2^{\circ} 00^{\prime} 30 " \mathrm{E}\right)$.

DNA extraction, amplification and sequencing of $18 S$ rDNA fragments

DNA was extracted using the PowerSoil DNA Extraction Kit (MoBio, Carlsbad, CA, USA) from biomass collected onto $0.2 \mu \mathrm{m}$ pore-size filters. $18 \mathrm{~S}$ rDNA fragments of ca. $550 \mathrm{bp}$, encompassing the V4 hypervariable region, were PCR amplified with primers EK-565F (5'-GCAGTTAAAAAGCTCGTAGT -3'; Simon et al., 2014) and 18S-EUK-1134-RUnonMet (5'-TTTAAGTTTCAGCCTTGCG-5') biased against Metazoa (Bower et al., 2004). These primers were tagged with twenty $10 \mathrm{bp}$ MIDs (Molecular IDentifiers) to allow differentiation of amplicons in the pools of 20 samples multiplexed for sequencing. 
PCRs were conducted in $25 \mu$ l reaction mix containing $1.5 \mathrm{mM} \mathrm{MgCl}_{2}, 0.2 \mathrm{~mm}$ dNTPs, $0.3 \mu \mathrm{m}$ primers, 0.3-3 $\mu$ l eluted DNA and 0.5 U HotStart Taq-Platinum polymerase (Invitrogen, Carlsbad, CA, USA). Twentyfive amplification cycles $\left(94^{\circ} \mathrm{C}\right.$ for $30 \mathrm{~s}, 58^{\circ} \mathrm{C}$ for $45 \mathrm{~s}$ and $72^{\circ} \mathrm{C}$ for $90 \mathrm{~s}$ ) were preceded by a 3-min denaturation step $\left(94^{\circ} \mathrm{C}\right)$ and ended by $10 \mathrm{~min}$ at $72^{\circ}$ $\mathrm{C}$ for final extension. Five to eleven independent PCR products for each sample were pooled together. Amplicons were then purified using the QIAquick PCR Purification Kit (Qiagen, Hilden, Germany). Equivalent amounts of purified amplicons (200$400 \mathrm{ng}$, depending on pools) for 20 different samples were pooled and pyrosequenced using the 454 GSFLX Titanium technology from Roche (Beckman Coulter Genomics, Danvers, MA, USA).

\section{Pyrosequence analysis}

We obtained a total of 1511901 reads. To remove potential spurious sequences, several filters were applied using a modified local pipeline (Simon et al., 2014). Short ( $<350 \mathrm{bp}$ ) or too long reads ( $>550$ $\mathrm{bp}$ ), reads containing errors in primers/MIDs or positions with undetermined bases and without the two flanking primer sequences were eliminated. At this stage, forward and reverse reads for each MID were separated and, for clustering purposes only, a single read from $100 \%$ identical sequences was retained. Pairwise flowgram alignments were clustered and treated with the PyroNoise program of AmpliconNoise (Quince et al., 2011) to eliminate further PCR and pyrosequencing errors. A total of 1272748 reads from all samples were retained (Supplementary Table S2). Forward and reverse reads were assembled for each sample and primers eliminated, before their analysis by the SeqNoise program of AmpliconNoise. Sequences from all samples were then processed together and clustered into operational taxonomic units (OTUs; 98\% similarity cutoff) using CD hit (Fu et al., 2012), before the generation of OTU frequency tables for the different samples using previously retained read information. Singletons, that is, OTUs composed of only one read, were eliminated for precaution. The most abundant sequence in each OTU was used as reference and blasted against the PR2 database (Guillou et al., 2013) to assign OTUs to taxonomic groups based on sequence similarity. OTUs affiliated to cryptophyte nucleomorphs were excluded from our analysis. Potential chimerical OTUs were eliminated using a stringent procedure with automated and manual steps as described in Simon et al. (2014). A total of 3742 OTUs were retained. Filtered sequences from these OTUs were then attributed to the different samples according to their MIDs.

\section{Statistical analyses}

All statistical analyses were conducted with the $\mathrm{R}$ software (http://cran.r-project.org) (R Development Core Team, 2013). Diversity and richness indices were determined using the 'Vegan' R-package (Oksanen et al., 2013). Richness was evaluated by rarefaction analyses as the estimated number of OTUs in a random subsample of each sequence library, which is of the same size as the smallest one (Hurlbert, 1971). The Simpson index was calculated as $D^{\prime}=1-\sum_{i=1}^{S}\left(f i^{2}\right)$ (Simpson, 1949) and evenness as $e=\left(-\sum_{i=1}^{S} f i \ln (f i)\right) / \ln (S)$ (Pielou, 1966), with $S$ being the observed number of OTUs and $f_{i}$ the relative frequency of each $\mathrm{OTU}_{i}$ in the sample. Pairwise Bray-Curtis dissimilarities between samples were calculated on the basis of OTU relative frequencies, instead of raw sequence counts to remove bias due to variable sequence numbers per sample, or on OTU frequencies after Wisconsin standardization, to balance rare versus abundant OTU weight (Bray and Curtis, 1957). Boxplots were drawn with notches to compare the distribution of Bray-Curtis dissimilarities or diversity and richness estimators between different classes (Chambers et al., 1983). Non-metric multidimensional scaling ordination analyses were conducted on Bray-Curtis dissimilarities based on square-root-transformed and Wisconsin-standardized OTU percentages, using the 'Vegan' R package. Ellipses grouping various classes were drawn using s.class from the 'Ade4' $\mathrm{R}$ package (Dray and Dufour, 2007). Permutational multivariate analyses of variance using distance matrices (Anderson, 2001) were conducted using Bray-Curtis dissimilarities calculated on OTU read percentages, with the Adonis function of the 'Vegan' package. Venn diagrams showing shared OTUs between ecosystems were drawn using the 'gplots' R-package (Bolker et al., 2012) on pooled sequences from monthly samples. To study seasonality, pairwise Bray-Curtis dissimilarities between each sample from the first sampling year and the samples from the same system 1-12 months apart were calculated. Then, the mean and standard errors of Bray-Curtis dissimilarities between samples separated by the same number of months were computed. To compare sample's principal component analyses were computed on their centered and scaled environmental characteristics using the 'Ade4' R-package; missing values were replaced by the average value of the parameter. To distinguish 'not available' from 'very low' values for analysis, nutrient concentrations below kit detection limits were set as the limit value minus a small random number (normal distribution $\left.\mu=0 ; \quad \sigma=10^{-6}\right)$. Canonical correspondence analyses (CCA) including the defined environmental parameters and the 37 most commonly abundant OTUs (those detected in at least 25\% of samples, that is, 28 samples, and with $\geqslant 0.1 \%$ mean relative abundance per sample; Supplementary Table S3) were calculated with 'Ade4' applying Wisconsin standardization. The proportion of community variance explained by environmental parameters was estimated as the ratio of the sum of eigenvalues from the CCA over the one of a CCA conducted on the same standardized OTU proportions (Borcard et al., 1992). 


\section{Results}

Temporal variation of environmental parameters The systems under study, four ponds and one brook, were initially chosen because of their contrasted physicochemical features (Simon et al., 2014). During the sampling period (April 2011-April 2013), these ecosystems experienced large incoming radiation and water temperature variations, as expected in temperate areas (Supplementary Table S1 and Supplementary Figures S1 and S2). The Mare Gabard had the lowest $\mathrm{pH}$ (6.2 on average), high chlorophyll $a$ and low nitrite concentrations. Saint Robert was characterized by episodic peaks of ammonia in July 2012 and January 2013 and very high chlorophyll $a$ concentrations in the summer and autumn. The Etang des Vallées was usually the most oxygenated and had the lowest dissolved orthophosphate concentrations. Two systems underwent desiccation, the $\mathrm{Ru}$ Sainte Anne (brook), characterized by low chlorophyll $a$ and high conductivity, in August and September 2012, and La Claye, characterized by low nitrite and ammonia, in July-December 2011 and September 2012 (Supplementary Table S1 and Supplementary Figures S1 and S2). Except for temperature and incoming radiation, the rest of the physicochemical parameters did not display apparent patterns of variation.

\section{Overall composition of protist communities}

We analyzed the diversity of small eukaryotes (0.2$5 \mu \mathrm{m}$ cell-size fraction) in 112 water samples collected along 24 months in the five ecosystems based on $18 \mathrm{~S}$ rDNA amplicon pyrosequencing. We obtained a total of 1272748 quality-filtered reads that grouped within 3742 OTUs (Supplementary Table S2), among which only two OTUs (represented by 164 and 145 qualityfiltered reads) were affiliated to metazoans. Most OTUs $(93.1 \%)$ occurred at low abundance $(<0.05 \%$ reads per sample, on average). Only 26 OTUs $(0.7 \%$ total) were relatively abundant $(>0.5 \%$ reads per sample) making, on average, $51.4 \%$ reads per sample.

The phylogenetic diversity of OTUs covered all currently recognized supergroups (Adl et al., 2012), Opisthokonta, Amoebozoa, Excavata, Archaeplastida, SAR (Stramenopiles-Alveolata-Rhizaria) and taxa of uncertain position in the eukaryotic tree (Cryptophyta, Centroheliozoa, Telonemida, Haptophyta, Katablepharida, Ancyromonadida and Apusozoa). In all, $10.6 \%$ of the OTUs could not be assigned to specific taxa based on sequence similarity (on average, $2.3 \%$ reads per sample). Stramenopiles, alveolates, cryptophytes, opisthokonts and archaeplastids were the most abundant groups (Figure 1). In addition to being abundant (up 35.1\% reads per sample), stramenopiles were diverse, encompassing 956 OTUs $(25.5 \%$ of all OTUs). Most of them affiliated to Chrysophyceae-Synurophyceae, the most abundant stramenopile group ( $20.0 \%$ reads per sample). They were followed by Bacillariophyceae, Raphidophyceae, Dictyochophyceae,
Bicosoecida and Oomyceta ( $>1 \%$ reads per sample, on average) and other, less abundant groups, such as MAST lineages, Labyrinthulida or Xanthophyceae (Supplementary Figure S3C). Alveolates were the second most abundant supergroup, representing $20.9 \%$ reads per sample on average, and included members of the Perkinsea, Colpodellida, Dinophyta and Apicomplexa, although ciliates dominated both in terms of abundance $(18.2 \%$ reads per sample, on average) and diversity (10.8\% of all OTUs) (Figure 1 and Supplementary Figure S3C). The parasitic Perkinsea were occasionally highly abundant, reaching up to $32.4 \%$ of the reads in Etang des Vallées in June 2012 (Figure 1). Cryptophytes were as abundant as Alveolates ( $20.8 \%$ reads per sample) but were little diverse (only $1.4 \%$ of OTUs).

Opisthokonts represented $9.9 \%$ of the reads per sample, on average, and were largely dominated by fungi ( $8.8 \%$ reads per sample, on average), especially chytridiomycetes, ascomycetes and basidiomycetes (Supplementary Figure S3C). Cryptomycota/Rozellids, choanoflagellates and ichthyosporeans were less abundant $(<0.6 \%)$, but occasionally reached higher proportions, for example, cryptomycota $(5.7 \%$ reads in Mare Gabard, January 2013) or choanoflagellates (6.1\% reads in Etang des Vallées, July 2012) (Figure 1). Archaeplastida, especially chlorophytes, were detected in relative high proportion (Supplementary Figure S3C). Several OTUs of streptophytes, rhodophytes and glaucophytes were occasionally recorded (Figure 1). Only OTU-2122 belonged to the rarely detected glaucophytes; it affiliated to Cyanophora paradoxa (99.6\% sequence identity), and was detected twice at low relative proportion in Saint Robert. Rhizarians and katablepharids were detected in rather low proportion (ca. $2 \%$ ), although the latter were always more relatively abundant in Etang des Vallées (4.8\% reads on average) (Figure 1) and occasionally peaked at high proportions elsewhere (for example, $52.5 \%$ reads in Saint Robert, March 2013) (Figure 1). Rhizarians were only represented by the fairly diverse cercozoans $(7.7 \%$ OTUs). Excavata were rather rare in general (Supplementary Figure S3C), with the exception of OTU-1147, affiliated to Trimastix pyriformis (98.6\% sequence identity), which represented $6.5 \%$ of the reads in the Ru Sainte Anne in July 2011. Amoebozoan, haptophytes, centroheliozoans, telonemids, apusomonads and ancyromonads were also detected, although at lower diversity and abundances (Supplementary Figure S3C). Centroheliozoans could only be detected once in Saint Robert and La Claye and twice in the $\mathrm{Ru}$ Sainte Anne. Similarly, some OTUs affiliated to Conosa, Excavata, Rhodophyta and Apicomplexa were rarely detected (fewer than 10 samples).

\section{Contrasted communities in the different ecosystems} Considered globally, protist communities strongly differed between the five shallow systems, confirming previous observations at a single time point 

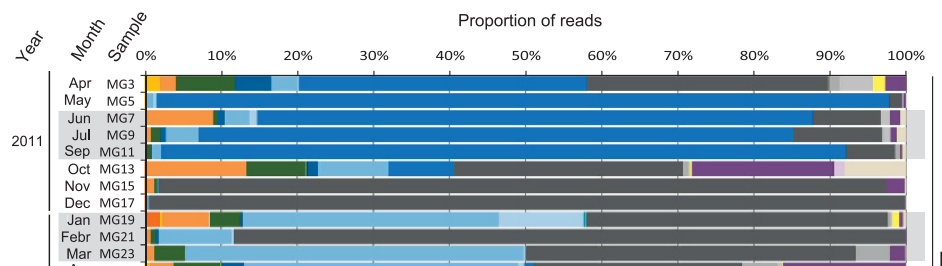

Mare Gabard

(MG)

\section{Saint Robert}

(SR)

\section{Etang des Colpodellida \\ Vallées}

(EV)

\section{Rhizaria \\ Cercozoa}

\section{Groups of uncertain \\ affiliation}

- Telonema

Katablepharida

Haptophyta

- Cryptophyta

Centroheliozoa

-Apusomonadida

Ancyromonadida

Ru Sainte

Anne

(RSA)

$\square$ Unassigned reads

Figure 1 Histograms showing the relative abundance of $18 \mathrm{~S}$ rDNA amplicon reads assigned to high-rank taxa, in all samples from the five ecosystems over the 2-years survey. Hatched bars correspond to missing data because of the drought periods: the Ru Sainte Anne was dried in August and September 2012, and La Claye from the end of July to December 2011 and in September 2012. 
(Simon et al., 2014). Only 50 out of the 3742 OTUs recorded during the 24-month sampling were shared by the five ecosystems (Figure 2a). They were mostly fungi within opisthokonts, chlorophytes within archaeplastids, ciliates within alveolates, chrysophytes within stramenopiles, cryptophytes, one cercozoan and one katablepharid. They were neither continuously abundant nor simultaneously present in all ecosystems (for example, ciliate OTU-356; Figure 3). From the 2663 OTUs ( $>71 \%$ of all OTUs) specific to one ecosystem, 1180 OTUs $(31.5 \%)$ were detected at least twice. Remarkably, $62.3 \%$ of the OTUs retrieved in the $\mathrm{Ru}$ Sainte Anne were not detected elsewhere. Some OTUs reached high abundances in one system without being detected in their closest neighbor; for instance, the Raphidophyceae OTU-15 in Mare Gabard (Figure 3).

The five ecosystems differed in richness, diversity and evenness. Richness was much higher in the brook than the ponds, while Mare Gabard and Saint Robert had the lowest richness (on average, 50.3 and
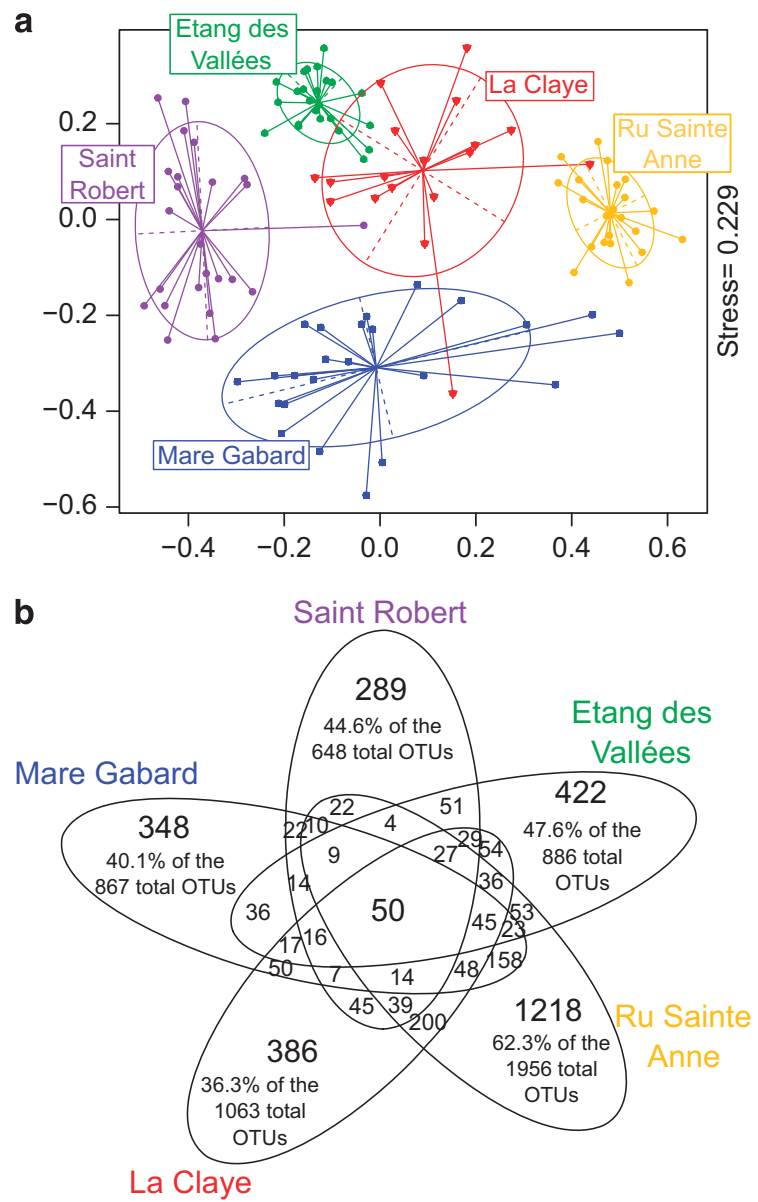

Figure 2 Distinct communities in the five freshwater ecosystems. (a) Non-metric multidimensional scaling plot, built on squareroot-transformed and Wisconsinstandardized Bray-Curtis dissimilarities between all samples. (b) Venn diagram showing the number of OTUs shared by several ecosystems or specific to an ecosystem. Proportions of OTUs specific to each ecosystem among all OTUs detected in this ecosystem are indicated. All samples from the 2-year survey are pooled for each ecosystem.
38.0 OTUs per sample, respectively) (Supplementary Figures S4 and S5). The same trend was observed for diversity and evenness estimates (Supplementary Figure S4).

Intersystem differences were clearly seen in nonmetric multidimensional scaling analyses based on Wisconsin-standardized OTU frequencies (Figure 2b). More than $20 \%$ of the total variation between samples was owing to the variance between ecosystems, as estimated by permutational multivariate analyses of variance using a Bray-Curtis distance matrix (Table 1). Etang des Vallées and La Claye seemed to host the most similar communities. They harbored, along with Saint Robert, the densest cryptophyte communities. Mare Gabard was dominated by stramenopiles (especially Raphidophyceae) and ciliates, and the $\mathrm{Ru}$ Sainte Anne by Chrysophyceae-Synurophyceae and fungi (Figure 1). Differences between ecosystems seemed to be due to the less frequent OTUs more than to the most abundant OTUs. Indeed, when frequencies for the different OTUs were not Wisconsin-standardized before non-metric multidimensional scaling (i.e. when the more an OTU is abundant in at least one sample, the more it influences sample cross-comparison), samples were no longer clustered per ecosystem (data not shown).

\section{Overall temporal dynamics of protist communities}

Within ecosystems, protist communities were highly dynamic, as shown by mean Bray-Curtis dissimilarities between all pairs of samples per ecosystem, ranging from 0.71 (Etang des Vallées) to 0.89 (Saint Robert) (Supplementary Figure S6A). The dissimilarities reached higher values after a Wisconsin standardization of OTU frequencies (0.88 for Etang des Vallées; 0.96 for Mare Gabard and Saint Robert; Supplementary Figure S6B), suggesting that infrequent OTUs varied more in abundance than frequent OTUs. This observed change in community structure over the 2 years was already suggested by the strong variations in richness observed, for example, more than 10 times in Mare Gabard (Supplementary Figure S4). The most stable protist community over time seemed that of the Etang des Vallées, showing the smallest Bray-Curtis distances between all pairs of samples (Supplementary Figure S6).

Despite changes in community composition with time, eukaryotic communities in each system did not differ importantly between the 2 years of the survey. A maximum of $9.8 \%$ of the total variance was recorded between interannual samples (recorded in Mare Gabard; Table 1). A clear seasonal pattern was observed in each ecosystem (Figure 4). Pairwise Bray-Curtis dissimilarities were highest between samples separated by 5 to 6 months, that is, samples from opposite seasons, and lowest between samples separated by 12 months or contiguous samples, that is, samples from the same season (Figure 4). This pattern was less smooth for La Claye likely because of missing data because of the 6 months of drought. 
Table 1 Variance partitioning between classes (Adonis)

\begin{tabular}{|c|c|c|c|c|c|c|c|c|c|c|c|c|}
\hline \multirow[b]{2}{*}{ Samples } & \multicolumn{2}{|c|}{ Ecosystems } & \multicolumn{2}{|c|}{ Seasons } & \multicolumn{2}{|c|}{ Sampling years } & \multicolumn{2}{|c|}{$\begin{array}{c}\text { Ecosystems } \sim \\
\text { Seasons }\end{array}$} & \multicolumn{2}{|c|}{$\begin{array}{l}\text { Ecosystems } ~ \\
\text { Sampling years }\end{array}$} & \multicolumn{2}{|c|}{$\begin{array}{c}\text { Sampling years } \\
\text { Seasons }\end{array}$} \\
\hline & F.Model $^{\mathrm{a}}$ & $R 2_{2}^{\mathrm{b}}$ & F.Model & $\mathrm{a} \quad R 2_{2}^{\mathrm{b}}$ & F.Model $^{\mathrm{a}}$ & $R 2_{2}^{\mathrm{b}}$ & F.Model $^{\mathrm{a}}$ & $R 2_{2}^{\mathrm{b}}$ & F.Model $^{\mathrm{a}}$ & $R 2_{2}^{\mathrm{b}}$ & F.Model $^{\mathrm{a}}$ & $R 2_{2}^{\mathrm{b}}$ \\
\hline All & & 631 & 2.5939 & 0.04738 & 2.0872 & 0.01271 & & & & & 1.2306 & 0.02246 \\
\hline Gabard pond & & & 4.4853 & 0.35753 & 3.773 & 0.09807 & & & & & 1.6486 & 0.41586 \\
\hline Saint Robert pond & & & 1.6863 & 0.19161 & 2.4289 & 0.092 & & & & & 0.9714 & 0.11038 \\
\hline Etang des Vallées & & & 2.19928 & 0.24628 & 1.2112 & 0.04521 & & & & & 0.99371 & 0.11128 \\
\hline Sainte Anne brook & & & 1.9582 & 0.23905 & 1.2828 & 0.0522 & & & & & 1.1392 & 0.13907 \\
\hline La Claye pond & & & 1.5829 & 0.24404 & 1.1955 & 0.06658 & & & & & 1.2073 & 0.12408 \\
\hline
\end{tabular}

Interactions between classes are indicated by 'class A class B'.

${ }^{\mathrm{a}} \mathrm{F} . \mathrm{Model}=\frac{\text { Sum of squares of distances between classes } / \text { degrees of freedom }}{\text { Sum of squares of distances inside classes / degrees of freedom }}$

${ }^{\mathrm{b}} R^{2}=1-\frac{\text { Sum of squares of distances inside classes }}{\text { Sum of squares of distances between all sample pairs }}$

Although seasonality was visible in all systems, its intensity varied for each ecosystem as attested by the proportion of community composition variance corresponding to variations between seasons ranging from 19.2\% (Saint Robert) to 35.8\% (Mare Gabard) (Table 1), and between seasons. Eukaryotic communities differed more between summer and winter than between autumn and spring, as revealed by non-metric multidimensional scaling analyses (Supplementary Figure S7).

\section{Temporal variation of specific protist taxa}

The relative proportions of diverse taxonomic groups fluctuated greatly and rapidly (as seen at a monthly scale) over the 2 years (Figure 1 and Supplementary Figure S8), most often because of changes in a few OTUs, which occasionally shifted proportions $>100$ times in two consecutive months (for example, cryptophytes in La Claye in December 2012 and January 2013; Supplementary Figure S8). Globally, taxonomic groups were rarely detected at high relative proportions in more than two consecutive months. Successive peaks of relative abundances were either due to the rapid dynamics of the same OTUs (for example, katablepharids in Etang des Vallées) or to raises in proportions of distinct OTUs (for example, bicosoecids in Saint Robert). Low-frequency groups could occasionally peak at noticeable frequency. This was the case of excavates (OTU-1147) in Ru Sainte Anne, September 2011 (Figure 1 and Supplementary Figure S8).

To test whether environmental conditions affected the dynamics of the most abundant protists in our ecosystems, we carried out statistical analyses to see potential correlations between the 37 widespread OTUs representing at least $0.1 \%$ reads per sample, on average, and occurring in at least 25\% samples (Supplementary Table S3) and various physicochemical parameters (our local measurements and meteorological data recorded at the closest meteorological stations; see Materials and methods). Physicochemical data-only and both physicochemical plus climatologic parameters explained $18.7 \%$ and $21.9 \%$ of the OTU's variance, respectively. As shown by CCA, fungi positively correlated with conductivity, whereas ciliates showed a negative correlation (Figure 5). Chlorophyte frequency seemed to correlate with chlorophyll $a$ (as expected) and phosphate. Cryptophytes seemed most abundant when dissolved oxygen and nitrite were higher, but their association with environmental variables was less clear.

At finer scales, individual OTUs showed variable patterns of temporal change. Very few OTUs were continuously recorded during the survey: 1, 0, 2, 1 and 7 OTUs in, respectively, Mare Gabard, Saint Robert, Ru Sainte Anne, La Claye and Etang des Vallées (for example, OTUs 55 and 356; Figure 3). Within low-frequency OTUs, two types of patterns were observed. In one pattern, displayed by 275 OTUs $(7.3 \%$ total), OTUs always represented $<0.05 \%$ reads per sample, although they were detected in at least two samples of the whole survey, sometimes reproducibly in consecutive years (for example, OTU-2986, affiliated to stramenopiles; Figure 3). Approximately $23 \%$ of these OTUS were fungi. The second pattern corresponded to several OTUs at low abundance most of the time, but being able to occasionally reach high relative proportions (for example, OTU-369; Figure 3). Thus, 47 OTUs (fungi, stramenopiles, cercozoans, chlorophytes, alveolates, excavates and centroheliozoans) represented $>0.5 \%$ reads in one sample and were not detected elsewhere. Among the most abundant and frequent OTUs, some presented a marked seasonality. In particular, OTU 15, corresponding to the flagellate algae Gonyostomum semen (Raphidophyceae), bloomed repeatedly and persistently in summertime in the Mare Gabard, reaching up to $98 \%$ reads in September 2012 (Figure 3). Also, a few OTUs 
remained abundant during the 2-year survey without apparent seasonal pattern: 3, 4, 6, 5 and 15 OTUs represented $>0.5 \%$ reads in at least half of the samples in Mare Gabard, Saint Robert, Ru Sainte Anne, La Claye and Etang des Vallées (for example, OTU-55, Figure 3), respectively. These OTUs were affiliated to chrysophytes and fungi in Sainte Anne, and mainly to ciliates, cryptophytes and stramenopiles elsewhere. Finally, a small set of OTUs that were always abundantly detected in some systems were little abundant or episodic in other environments, for example, katablepharid OTU-55 (Figure 3).

\section{Temporal dynamics of functional groups}

To get an insight on temporal variation of major protist functions, we tentatively and roughly classified the detected OTUs in three major functional groups on the basis of their taxonomic affiliation: primary producers, free-living heterotrophs and parasites. Primary producers comprised obligate phototrophs (for example, chlorophytes) and mixotrophs (for example, cryptophytes), whereas freeliving heterotrophs included phagotrophic predators (for example, ciliates, choanoflagellates) or osmotrophs (mostly fungi). Parasites included Perkinsea (Mangot et al., 2010), LKM11-RozellidaCryptomycota, Ichthyosporea, Oomycota and Apicomplexa, often observed in freshwater systems (Richards et al., 2005; Lepère et al., 2008; Lara et al., 2010; Jones et al., 2011; Triadó-Margarit and Casamayor, 2012; Taib et al., 2013) (see in Supplementary Figure S9 lineages included in each category). The relative proportions of the three groups varied differently among ecosystems. In Mare Gabard, primary producers were largely dominant in summer (mostly due to Goniostomum semen blooms) and heterotrophs in winter, whereas in other systems primary producers tended to dominate in spring (Supplementary Figure S9). Parasites had generally low relative proportions in Saint Robert, La Claye and Mare Gabard, with the exception of November 2012February 2013 in Mare Gabard where Perkinsea and Cryptomycota-Rozellida were recorded at significant proportions. Perkinsids reached important proportions in the Etang des Vallées, whereas Oomycota, Perkinsea and Cryptomycota/Rozellids were non-negligible components of Ru Sainte Anne communities.

Interestingly, even if the relative proportions of the three categories varied differently, the integrated annual relative proportions of producers, free-living heterotrophs and parasites were remarkably similar between the five ecosystems, especially the ponds (Figure 6). Only the $\mathrm{Ru}$ Sainte Anne deviated somewhat from that proportionality, having a lower proportion of primary producers and a higher proportion of free-heterotrophs as compared with the other systems.

\section{Discussion}

Integrating time scales extends our perception of protist biodiversity

The diversity of small protists in the five shallow ecosystems studied over 24 months was large, including members of all eukaryotic supergroups and phyla of uncertain position (Figure 1). Stramenopiles, alveolates and cryptophytes generally dominated; green algae and fungi+cryptomycota were also common, as often observed in other freshwater systems (Lefranc et al., 2005; Richards et al., 2005; Šlapeta et al., 2005; Lepère et al., 2008; Mangot et al., 2012; Triadó-Margarit and Casamayor, 2012; Taib et al., 2013). We detected a total of 3742 stringently defined OTUs, which represent a number 6 to 11 times higher than that of OTUs observed at any discrete date (for example, 812 OTUs in April 2012; Simon et al., 2014). Every month, previously unseen phylotypes were identified and saturation was not approached even after 24 months, especially for $\mathrm{Ru}$ Saint Anne, as the species accumulation curves appeared to be leveling off for the ponds but not the stream (Supplementary Figure S5).

This not only supports previous observations suggesting that small freshwater systems, perhaps more than larger lakes, are reservoirs of protist diversity (Šlapeta et al., 2005; Downing et al., 2006; Downing, 2010; Simon et al., 2014) but, critically, highlights the importance of including temporal scales in biodiversity and microbial ecology studies. The impact of doing so is manifold. Obviously, as temporal surveys allow detecting a wider diversity than time-point studies (Nolte et al., 2010), this will influence comparative diversity analyses and conclusions about lineages specific to given habitats. For instance, in April 2012 we detected in these freshwater systems a few OTUs belonging to the 'typically marine' stramenopile lineages MAST-2, MAST-12, MAST-3 and MAST-6 (Massana et al., 2014; Simon et al., 2014). If we include data from the 2-year survey, a total of 52 OTUs branched within these lineages (or at the base of some of them), reinforcing the idea that they are not ocean-specific (Supplementary Figure S10).

As for comparative diversity studies, including time scales might significantly affect conclusions about biogeography. Unfortunately, most studies for marine and large freshwater systems still include punctual samples taken at disparate time points. In our case, the fact that our five physically close (2$9.5 \mathrm{~km}$ ) freshwater ecosystems remained distinct over the two years (Figure 2) strongly argues in favor of environmental factors but not geographic distance as major community drivers, strengthening previous conclusions (Simon et al, 2014). Another hint pointing in that direction is that eukaryotic communities differed more between summer and winter than between autumn and spring (Supplementary Figure S7). This could be easily linked to seasonal variations of physico-chemical parameters, more 

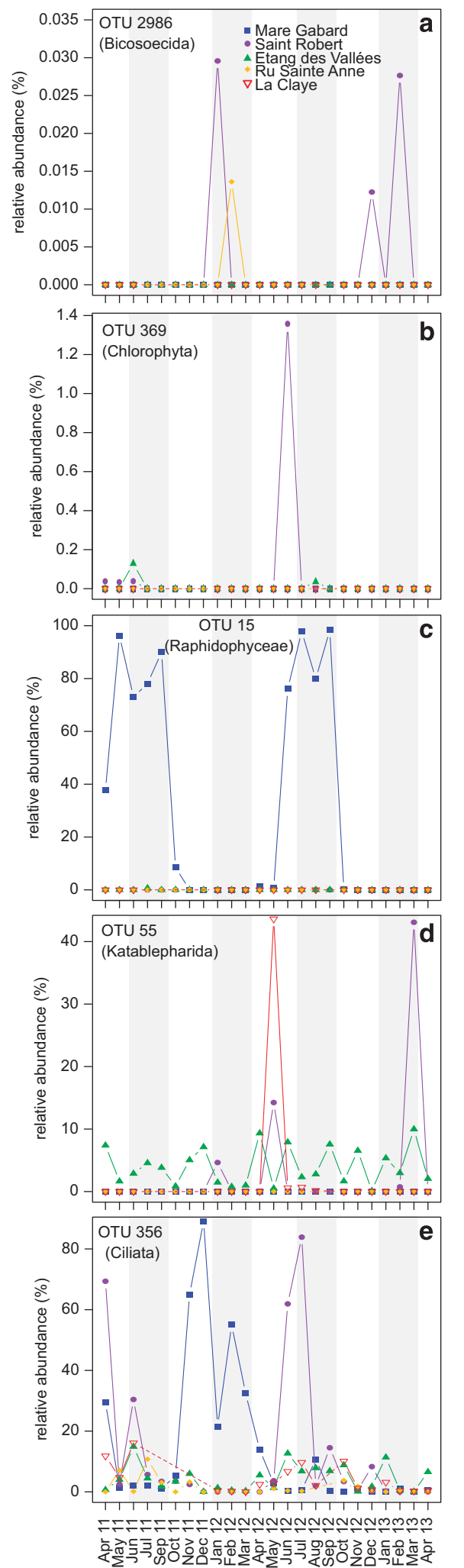

Figure 3 Relative abundance of five OTUs showing different types of dynamics, in samples from the five ecosystems, over the 2-year survey. Each color corresponds to the relative abundance (proportion of reads) dynamics in one of the sampled systems (see legend in Figure 1). The name and taxonomic affiliations of OTUs are indicated at each panel. Ru Sainte Anne dried in August and September 2012, and La Claye pond from the end of July to December 2011 and in September 2012. Missing data are indicated by dashed lines.

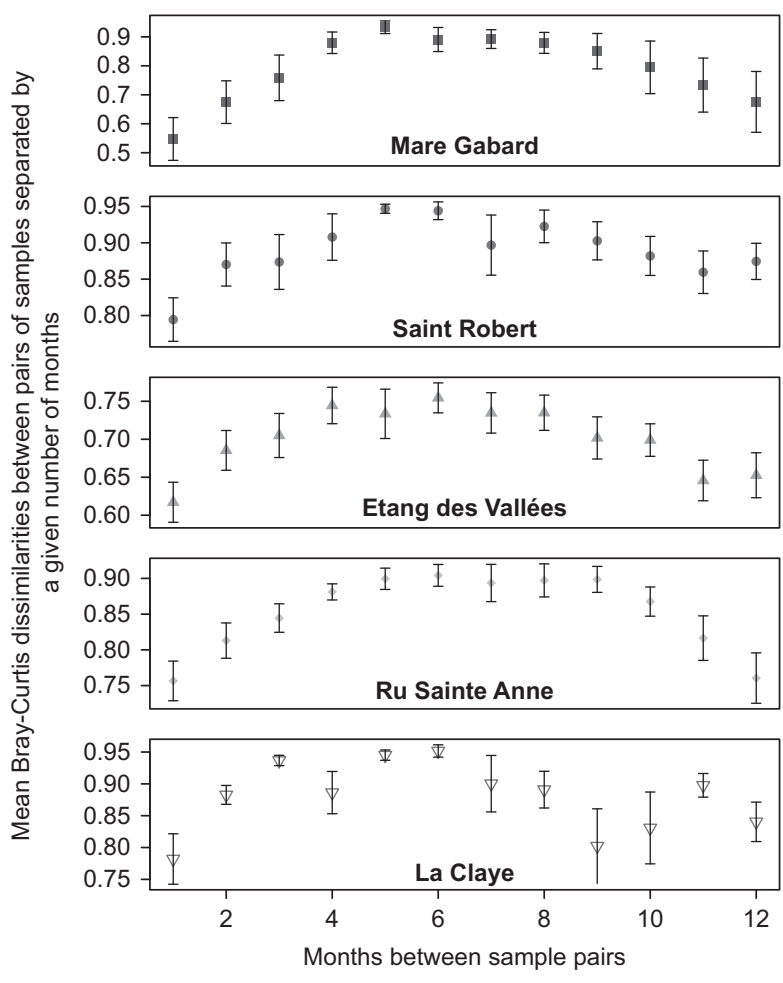

Figure 4 Pairwise Bray-Curtis dissimilarities between samples separated from 1 to 12 months. Each point represents the mean of pairwise Bray-Curtis dissimilarities between samples 1 to 12 months apart, plotted with standard errors. All means are based on 12 dissimilarities except for Ru Sainte Anne and La Claye pond because of missing data due to drought periods. The color reproduction of this figure is available on the ISME Journal journal online

similar in spring-autumn (Supplementary Figure S2). At a finer level, we could show some correlations between some taxonomic groups and measured environmental parameters (Figure 5). The clearest association was observed between fungi and high conductivity, which could result from their osmotrophic nutrition or from higher sediment input in waters. Cryptophytes correlated with oxygenated waters, as previously observed in ponds of different oxic levels (Šlapeta et al., 2005). However, our set of environmental parameters explained only a fifth $(22 \%)$ of the variation of the 37 most common OTUs tested. The detection of only few clear correlations may result from the lack of other influencing abiotic parameters but, most likely, biotic parameters, including predatory, mutualistic and/or parasitic interactions with prokaryotes, other eukaryotes (protists or metazoans) or viruses.

Finally, including temporal scales in diversity analyses also demonstrates that a perceptible component of the so-called 'rare biosphere' corresponds to organisms that experience temporal variation as a consequence of their lifestyle and/or that constitute a sort of 'seed bank' ready to respond to environmental cues (Pedrós-Alió, 2006; Caron and Countway, 2009; Lennon and Jones, 2011). Thus, even if in our systems most OTUs remained in low frequency 
during the 2 years, over 300 low-frequency OTUs peaked to noticeable and even high abundances at least once or twice (for example, Figure 3). Longer surveys (and at varying temporal frequency) are expected to reveal even higher proportions of non-rare organisms whose abundance fluctuates over time.

\section{Marked seasonality despite complex patterns of temporal dynamics}

Eukaryotic communities showed seasonal patterns, and were clearly differentiated in winter and summer (Table 1 and Supplementary Figure S7). However, the most striking observation of our study was that the seasonal pattern repeated during the second year in the five ecosystems (Figure 4) despite the fact that (i) the meteorology during the two was very different (2012 was hotter and drier), (ii) new OTUs were observed at each sampling point (Supplementary Figure S5) and (iii) that the patterns of variation of the different taxa, either at the level of phyla or OTUs, seemed generally complex and difficult to interpret (Figure 3 and Supplementary Figure S8). This implies that, despite observable differences in protist diversity, the overall community structure converges in similar periods in subsequent years, once again arguing in favor of an important role of environmental selection. Our results contrast with

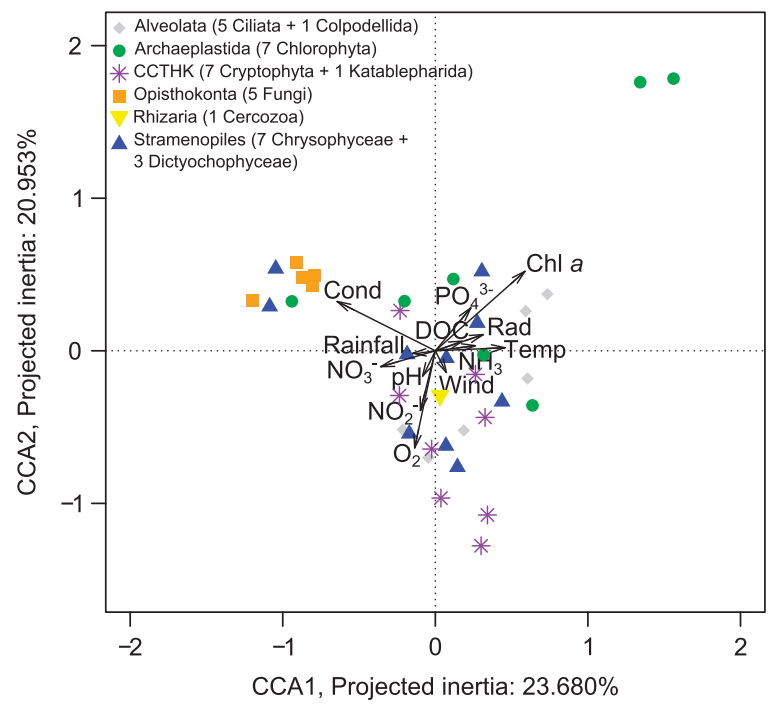

Figure 5 CCA plot. CCA was conducted on all samples and on the 37 OTUs detected in at least $25 \%$ of samples and having a mean relative abundance per sample of $0.1 \%$ or above, after a Wisconsin standardization. Both physicochemical parameters measured in the ecosystems' water and weather information were included in the analysis. Dots represent OTUs, with color and form indicating their taxonomic affiliation. CCTHK, Cryptophyta, Centroheliozoa, Telonema, Haptophyta, Katablepharida; Chl a, chlorophyll $a$; Cond, conductivity; DOC, dissolved organic carbon; Rad, mean daily solar radiation of the week before sampling; Rain, rainfall during the week before sampling; Temp, water temperature; Wind, mean wind speed at $10 \mathrm{~m}$ high during the sampling day. those carried out in some lakes, where community patterns did not appear to repeat over consecutive years (Lepère et al., 2006). This is surprising given that small freshwater systems (Downing et al., 2006; Céréghino et al., 2008; Downing, 2010) are much more variable than larger water bodies.

Deciphering seasonal dynamics at finer levels seems difficult at this stage and will require additional sampling and analysis. Seasonality has been observed for various microbial eukaryotes (for example, Bamforth, 1958; Hitchman and Jones, 2000; Lara et al., 2011). In our case, despite the large data set, a clear seasonality for most of the high-rank taxonomic groups was not observed (Figure 1 and Supplementary Figure S8). Some groups (for example, choanoflagellates, labyrinthulids, dictyochophytes) exhibited seasonal-like dynamics, but not necessarily in several ecosystems, and the peaks were sustained by only one or a small set of OTUs. Indeed, as observed previously (Nolte et al., 2010), community temporal variability was not only due to relative abundance changes in frequently detected OTUs but also to the appearance and disappearance of many phylotypes (Figure 3). Whether the recurrent observation of new OTUs (Supplementary Figure S5) is due to immigration of foreign microbes or to perennial low-abundance

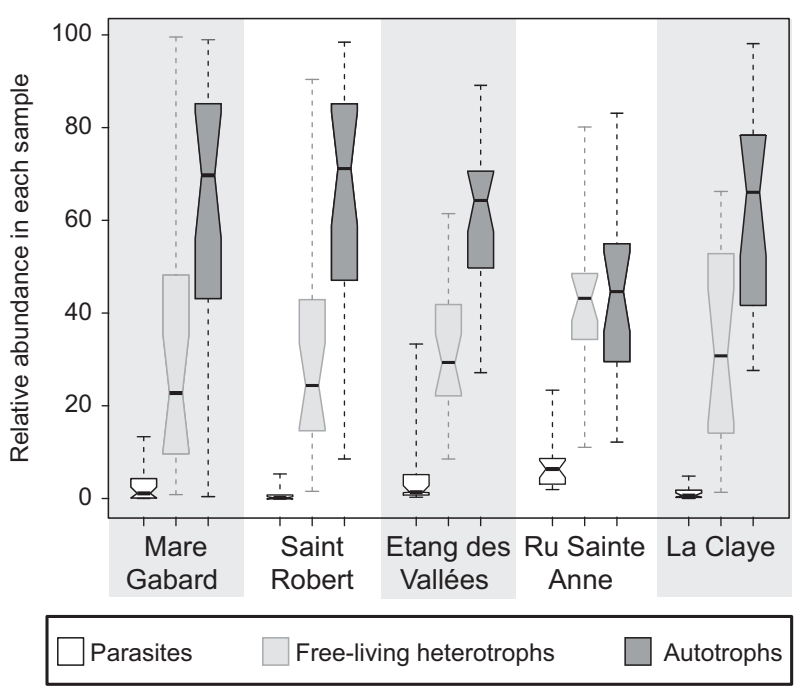

Figure 6 Distribution of relative abundances of reads affiliated to potential parasites, other heterotrophs and primary producers in all samples from the five ecosystems. The thickest line inside each box represents the median of the distribution, bottom and top borders of boxes correspond to the first and third quartiles and whiskers extend to minimal and maximal values. Notches are drawn to indicate whether medians of the three distributions can be considered as different for each ecosystem (Chambers et al., 1983, p. 62). Putative parasites: Apicomplexa, Rozellida, Oomyceta, Perkinsea, Ichthyosporea; potential other heterotrophs: Ancyromonadida, Apusomonadida, Bicosoecida, Centroheliozoa, Cercozoa, Choanoflagellida, Ciliophora, Colpodellida, Conosa, Discosea, Fungi, Katablepharida, Labyrinthulida, Lobosa, Malawimonadida, MAST, Metamonada, Telonema; putative primary producers: Bacillariophyceae, Chlorophyta, Chrysophyceae-Synurophyceae, Cryptophyta, Dictyochophyceae, Dinophyta, Glaucophyta, Haptophyta, Rhodophyta, Streptophyta, Xanthophyceae. 
eukaryotes occasionally observed above detection limits remains unsettled. As mentioned above, several OTUs seem to correspond to this category, being detected more than once along the survey. However, immigration may be also an important component. Although the atmospheric transport of microbes in lakes may not be significant (Jones and McMahon, 2009), migration may be facilitated by animals (here essentially deer, wild boars and a variety of small mammals, birds and amphibians), especially at few kilometer scales. Animals also stir bottom sediment and surrounding soils, further contributing to the input of foreign microbes. Immigration may be particularly important in the $\mathrm{Ru}$ Sainte Anne, the brook, which harbors the highest diversity (Table 1 and Supplementary Figures S4 and S5), as local communities are connected to those in upstream locations via the continuous water flow.

Insight into the ecology of small freshwater bodies In addition to repeated seasonal patterns of small eukaryotes observed in the ponds and brook, and despite the apparent complexity of individual taxon dynamics, other large-scale ecological indicators seem to emanate from our study. Analyzed collectively, some of them inform about, or correlate with, the trophic status of the different systems. For instance, the ponds Mare Gabard and Saint Robert have the lowest richness (and diversity estimates, although they are relatively high; Supplementary Table S1 and Supplementary Figure S4). However, protist diversity at Mare Gabard seems to be far from saturation, although that of Saint Robert seems to approach an asymptote (Supplementary Figure S5). This would be in agreement with Mare Gabard being a pristine forest pond, potentially more diverse, than Saint Robert, a highly eutrophic village pond highly impacted by agricultural and other associated human activities (Simon et al, 2014). On the opposite extreme, the Ru Sainte Anne and the Etang des Vallées have the largest richness and diversity indices, La Claye holding an intermediate position (Supplementary Table S1 and Supplementary Figure S4). However, while protist diversity at the Etang des Vallées seems to approach saturation, Ru Sainte Anne exhibits an exponential trend of OTU increase (Supplementary Figure S5). This may be partly explained by immigration being more abundant in the Ru Saint Anne. However, this seems also to imply that the Etang des Vallées, being the biggest, is the most stable of the five systems analyzed; its higher buffering capacity would explain a more longstanding diversity. Indeed, Bray-Curtis distances between sample pairs in the Etang des Vallées are significantly smaller than in the rest of ecosystems (Supplementary Figure S6).

The other interesting trend observed correspond to the repartition of functional categories (primary producers such as chlorophytes or cryptophytes, free-living heterotrophs, parasites) through time. Interestingly, even if the relative proportions of the three categories varied differently along the survey (Supplementary Figure S9), annual relative proportions of producers, free-living heterotrophs and parasites were highly similar in the four ponds (Figure 6). The only exception was the $\mathrm{Ru}$ Sainte Anne, which, comparatively, had remarkable lower proportions of primary producers and higher proportions of free heterotrophs, suggesting that the foodweb structure may be different in brooks. This might be explained both by a predominance of benthic primary production in a system characterized by running waters and by the presence of higher fungal abundances (osmotrophy) versus predators (phagotrophy), the latter dominating in the ponds. A higher osmotroph abundance might potentially be linked to incoming resources from runoff. Differences in the annual relative proportions of primary producers, free-living heterotrophs and parasites are thus suggestive of a fundamentally different food-web structure between lotic and lentic ecosystems, and would confirm differences previously observed at the bacterioplankton level (Portillo et al., 2012). In all systems, parasites were at comparable relative low levels, between 2 and $7 \%$ on average, with very rare peaks over $10 \%$, suggesting that this is the maximal parasite load that freshwater aquatic ecosystems can stably tolerate.

In summary, our study highlights the importance of analyzing temporal series for a comprehensive perception of microbial biodiversity, biogeography and ecology. Establishing microbial community pattern regularities and understanding their underlying causes, including functional constraints, as well as biotic and abiotic environmental determinants, will require considerable effort and constitutes the next important challenge in microbial ecology.

\section{Conflict of Interest}

The authors declare no conflict of interest.

\section{Acknowledgements}

We thank F Hardy, the Parc Naturel Régional de la Haute Vallée de Chevreuse and the Office National des Forêts du Parc de Rambouillet. We also thank Claude Yéprémian for providing his method for chlorophyll a quantitative analysis. This work was supported by funding from the CNRS EC2CO program and the European Research Council under the European Union's Seventh Framework Program ERC Grant Agreement 322669 'ProtistWorld'.

\section{References}

Adl SM, Simpson AGB, Lane CE, Lukeš J, Bass D, Bowser SS et al. (2012). The revised classification of eukaryotes. J Eukaryot Microbiol 59: 429-493. 
Anderson MJ. (2001). A new method for non-parametric multivariate analysis of variance. Austral Ecol 26: 32-46.

Bachy C, Dolan JR, López-García P, Deschamps P, Moreira D. (2013). Accuracy of protist diversity assessments: morphology compared with cloning and direct pyrosequencing of $18 \mathrm{~S}$ rRNA genes and ITS regions using the conspicuous tintinnid ciliates as a case study. ISME J 7: 244-255.

Bamforth SS. (1958). ecological studies on the planktonic protozoa of a small artificial pond. Limnol Oceanogr 3: 398-412.

Bolker B, Bonekakke L, Gentleman R, Liaw WHA, Lumley $\mathrm{T}$, Maechler $\mathrm{M}$ et al. (2012), gplots: Various R programming tools for plotting data. $\mathrm{R}$ package version 2.11.0. Available at: http://cran.r-project.org/package = gplots .

Borcard D, Legendre P, Drapeau P. (1992). Partialling out the spatial component of ecological variation. Ecology 73: 1045-1055.

Bower SM, Carnegie RB, Goh B, Jones SRM, Lowe GJ, Mak MSW. (2004). Preferential PCR amplification of parasitic protistan small subunit rDNA from metazoan tissues. J Eukaryot Microbiol 51: 325-332.

Bray JR, Curtis JT. (1957). An ordination of the upland forest communities of southern Wisconsin. Ecol Monogr 27: 325-349.

Caron DA, Countway P. (2009). Hypotheses on the role of the protistan rare biosphere in a changing world. Aquat Microb Ecol 57: 227-238.

Carrias J-F, Amblard C, Quiblier-Lloberas C, Bourdier G. (1998). Seasonal dynamics of free and attached heterotrophic nanoflagellates in an oligomesotrophic lake. Freshw Biol 39: 91-101.

Céréghino R, Biggs J, Oertli B, Declerck S. (2008). The ecology of European ponds: defining the characteristics of a neglected freshwater habitat. Hydrobiologia 597: $1-6$.

Chambers JM, Cleveland WS, Kleiner B, Tukey PA. (1983). Graphical Methods for Data Analysis. Wadsworth \& Brooks/Cole.

Cloern JE. (1996). Phytoplankton bloom dynamics in coastal ecosystems: a review with some general lessons from sustained investigation of San Francisco Bay, California. Rev Geophys 34: 127-168.

Diez B, Pedrós-alió C, Massana R. (2001). Study of genetic diversity of eukaryotic picoplankton in different oceanic regions by small-subunit rRNA gene cloning and sequencing. Appl Environ Microbiol 67: 2932-2941.

Dobell C. (1932). Antony van Leeuwenhoek and his 'Little Animals' Being Some Account of the Father of Protozoology and Bacteriology and his Multifarious Discoveries in these Disciplines Collected, Translated, and Edited, from his Printed Works, Unpublished Manuscripts Harcourt, Brace and company: New York, NY.

Downing JA. (2010). Emerging global role of small lakes and ponds: little things mean a lot. Limnetica 1: 9-24.

Downing JA, Duarte CM, Tranvik LJ, Striegl RG, McDowell WH, Kortelainen P et al. (2006). The global abundance and size distribution of lakes, ponds, and impoundments. Limnol Oceanogr 51: 2388-2397.

Dray S, Dufour A-B. (2007). The ade4 Package: implementing the duality diagram for ecologists. J Stat Softw 22: $1-20$.

Fu L, Niu B, Zhu Z, Wu S, Li W. (2012). CD-HIT: accelerated for clustering the next-generation sequencing data. Bioinformatics 28: 3150-3152.
Giovannoni SJ, Vergin KL. (2012). Seasonality in ocean microbial communities. Science 335: 671-676.

Guillou L, Bachar D, Audic S, Bass D, Berney C, Bittner L et al. (2013). The Protist Ribosomal Reference database (PR2): a catalog of unicellular eukaryote small sub-unit rRNA sequences with curated taxonomy. Nucleic Acids Res 41: D597-D604.

Hitchman RB, Jones HLJ. (2000). The role of mixotrophic protists in the population dynamics of the microbial food web in a small artificial pond. Freshw Biol 43: 231-241.

Hurlbert SH. (1971). The nonconcept of species diversity: a critique and alternative parameters. Ecology 52: 577-586.

Jardillier L, Zubkov M V, Pearman J, Scanlan DJ. (2010). Significant $\mathrm{CO}_{2}$ fixation by small prymnesiophytes in the subtropical and tropical northeast Atlantic Ocean. ISME J 4: 1180-1192.

Jones MDM, Richards TA, Hawksworth DL, Bass D. (2011). Validation and justification of the phylum name Cryptomycota phyl. nov. IMA Fungus 2: 173-175.

Jones SE, McMahon KD. (2009). Species-sorting may explain an apparent minimal effect of immigration on freshwater bacterial community dynamics. Environ Microbiol 11: 905-913.

Jordan R, Chamberlain A. (1997). Biodiversity among haptophyte algae. Biodivers Conserv 6: 131-152.

Kalff J, Knoechel R. (1978). Phytoplankton and their dynamics in oligotrophic and eutrophic lakes. Annu Rev Ecol Syst 9: 475-495.

Kim DY, Countway PD, Jones AC, Schnetzer A, Yamashita W, Tung C et al. (2014). Monthly to interannual variability of microbial eukaryote assemblages at four depths in the eastern North Pacific. ISME J 8: 515-530.

Kim E, Harrison J. (2011). Newly identified and diverse plastid-bearing branch on the eukaryotic tree of life. Proc Natl Acad Sci USA 108: 1496-1500.

Lara E, Mitchell EAD, Moreira D, López-García P. (2011). Highly diverse and seasonally dynamic protist community in a pristine peat bog. Protist 162: 14-32.

Lara E, Moreira D, López-García P. (2010). The environmental clade LKM11 and Rozella form the deepest branching clade of fungi. Protist 161: 116-121.

Lefranc M, Thénot A, Lepère C, Debroas D. (2005). Genetic diversity of small eukaryotes in lakes differing by their trophic status. Appl Environ Microbiol 71: 5935-5942.

Lennon JT, Jones SE. (2011). Microbial seed banks: the ecological and evolutionary implications of dormancy. Nat Rev Microbiol 9: 119-130.

Lepère C, Boucher D, Jardillier L, Domaizon I, Debroas D. (2006). Succession and regulation factors of small eukaryote community composition in a lacustrine ecosystem (Lake Pavin). Appl Environ Microbiol 72: 2971-2981.

Lepère C, Domaizon I, Debroas D. (2008). Unexpected importance of potential parasites in the composition of the freshwater small-eukaryote community. Appl Environ Microbiol 74: 2940-2949.

Li WKW. (1994). Primary production of prochlorophytes, cyanobacteria, and eucaryotic ultraphytoplankton: measurements from flow cytometric sorting. Limnol Oceanogr 39: 169-175.

López-García P, Rodríguez-Valera F, Pedrós-Alió C, Moreira D. (2001). Unexpected diversity of small eukaryotes in deep-sea Antarctic plankton. Nature 409: 603-607. 
Mangot J-F, Debroas D, Domaizon I. (2010). Perkinsozoa, a well-known marine protozoan flagellate parasite group, newly identified in lacustrine systems: a review. Hydrobiologia 659: 37-48.

Mangot J-F, Domaizon I, Taib N, Marouni N, Duffaud E, Bronner G et al. (2012). Short-term dynamics of diversity patterns: evidence of continual reassembly within lacustrine small eukaryotes. Environ Microbiol 15: 1745-1758.

Martiny JBH, Bohannan BJM, Brown JH, Colwell RK, Fuhrman JA, Green J et al. (2006). Microbial biogeography: putting microorganisms on the map. Nat Rev Microbiol 4: 102-112.

Massana R, Balagué V, Guillou L, Pedrós-Alió C. (2004). Picoeukaryotic diversity in an oligotrophic coastal site studied by molecular and culturing approaches. FEMS Microbiol Ecol 50: 231-243.

Massana R, Del Campo J, Sieracki ME, Audic S, Logares R. (2014). Exploring the uncultured microeukaryote majority in the oceans: reevaluation of ribogroups within stramenopiles. ISME J 8: 854-866.

Moon-van der Staay SY, De Wachter R, Vaulot D. (2001). Oceanic 18S rDNA sequences from picoplankton reveal unsuspected eukaryotic diversity. Nature 409: 607-610.

Nolte V, Pandey R, Jost S. (2010). Contrasting seasonal niche separation between rare and abundant taxa conceals the extent of protist diversity. Mol Ecol 19: 2908-2915.

Oksanen J, Blanchet FG, Kindt R, Legendre P, Minchin RP, O’Hara RB et al. (2013), vegan: Community Ecology Package. R package version 2.0-7. Available at: http:// cran.r-project.org/package = vegan .

Pedrós-Alió C. (2006). Marine microbial diversity: can it be determined? Trends Microbiol 14: 257-263.

Pielou EC. (1966). The measurement of diversity in different types of biological collections. J Theor Biol 13: 131-144.

Portillo MC, Anderson SP, Noah F. (2012). Temporal variability in the diversity and composition of stream bacterioplankton communities. Environ Microbiol 14: 2417-2428.

Quince C, Lanzen A, Davenport RJ, Turnbaugh PJ. (2011). Removing noise from pyrosequenced amplicons. BMC Bioinform 12: 38 .

R Development Core Team (2013), R: A Language and Environment for Statistical Computing. R version 2.15.3. Available at: http://www.r-project.org.

Reid PC, Lancelot C, Gieskes WWC, Hagmeier E, Weichart G. (1990). Phytoplankton of the North Sea and its dynamics: a review. Netherlands J Sea Res 26: 295-331.
Richards TA, Vepritskiy AA, Gouliamova DE, Nierzwicki-Bauer SA. (2005). The molecular diversity of freshwater picoeukaryotes from an oligotrophic lake reveals diverse, distinctive and globally dispersed lineages. Environ Microbiol 7: 1413-1425.

Simó R. (2001). Production of atmospheric sulfur by oceanic plankton: biogeochemical, ecological and evolutionary links. Trends Ecol Evol 16: 287-294.

Simon M, Jardillier L, Deschamps P, Moreira D, Restoux G, Bertolino $\mathrm{P}$ et al. (2014). Complex communities of small protists and unexpected occurrence of typical marine lineages in shallow freshwater systems. Environ Microbiol; doi:10.1111/1462-2920.12591.

Simpson EH. (1949). Measurement of diversity. Nature 163: $688-688$.

Šlapeta J, Moreira D, López-García P. (2005). The extent of protist diversity: insights from molecular ecology of freshwater eukaryotes. Proc $R$ Soc Ser $B$ 272: 2073-2081.

Sogin ML, Morrison HG, Huber JA, Mark Welch D, Huse SM, Neal PR et al. (2006). Microbial diversity in the deep sea and the underexplored 'rare biosphere'. Proc Natl Acad Sci USA 103: 12115-12120.

Søndergaard M, Jeppesen E, Jensen JP. (2005). Pond or lake: does it make any difference? Arch für Hydrobiol 162: 143-165.

Taib N, Mangot J-F, Domaizon I, Bronner G, Debroas D. (2013). Phylogenetic affiliation of SSU rRNA genes generated by massively parallel sequencing: new insights into the freshwater protist diversity. PLoS One 8: e58950.

Triadó-Margarit X, Casamayor EO. (2012). Genetic diversity of planktonic eukaryotes in high mountain lakes (Central Pyrenees, Spain). Environ Microbiol 14: 2445-2456.

Vigil P, Countway P, Rose J, Lonsdale D, Gobler C, Caron DA. (2009). Rapid shifts in dominant taxa among microbial eukaryotes in estuarine ecosystems. Aquat Microb Ecol 54: 83-100.

Zhao B, Chen M, Sun Y, Yang J, Chen F. (2011). Genetic diversity of picoeukaryotes in eight lakes differing in trophic status. Can J Microbiol 57: 115-126.

Zinger L, Gobet A, Pommier T. (2012). Two decades of describing the unseen majority of aquatic microbial diversity. Mol Ecol 21: 1878-1896.

Zubkov M V, Tarran GA. (2008). High bacterivory by the smallest phytoplankton in the North Atlantic Ocean. Nature 455: 224-226.

Supplementary Information accompanies this paper on The ISME Journal website (http://www.nature.com/ismej) 